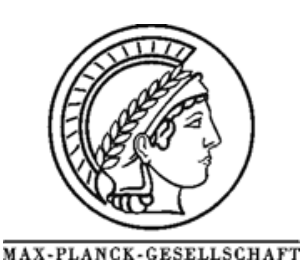

\title{
Adsorbate coverages and surface reactivity in methanol oxidation over Cu(110): An in situ photoelectron spectroscopy study
}

\author{
S. Günther ${ }^{1}$, L. Zhou ${ }^{2}$, R. Imbihl ${ }^{2}$, M. Hävecker ${ }^{3}$, A. Knop-Gericke ${ }^{3}$, E. Kleimenov ${ }^{3}$, R. Schlögl ${ }^{3}$ \\ ${ }^{1}$ Department Chemie, LMU München, Butenandtstr. 11 E, 80377 München, Germany \\ ${ }^{2}$ Institut für Physikalische Chemie und Elektrochemie, Callinstr. 3-3a, 30167 Hannover, Germany \\ ${ }^{3}$ Fritz-Haber-Institut der Max-Planck-Gesellschaft, Faradayweg 4-6, D-14195 Berlin, Germany
}

Received 24 March 2006; accepted 22 June 2006; published 20 September 2006

\begin{abstract}
The adsorbate species present during partial oxidation of methanol on a $\mathrm{Cu}(110)$ surface have been investigated in the $10^{-5}$ mbar range with in situ x-ray photoelectron spectroscopy (XPS) and rate measurements. Two reaction intermediates were identified, methoxy with a C $1 \mathrm{~s}$ binding energy (BE) of $285.4 \mathrm{eV}$ and formate with a C 1s BE of $287.7 \mathrm{eV}$. The $\mathrm{c}(2 \times 2)$ overlayer formed under reaction conditions is assigned to formate. Two states of adsorbed oxygen were found characterized by O 1s BE's of 529.6 and $528.9 \mathrm{eV}$, respectively. On the inactive surface present at low $\mathrm{T}$ around $300-350 \mathrm{~K}$ formate dominates while methoxy is almost absent. Ignition of the reaction correlates with a decreasing formate coverage. A large hysteresis of $\approx 200 \mathrm{~K}$ width occurs in T-cycling experiments whose correlation with adsorbate species was studied with varying oxygen and methanol partial pressures. The two branches of the hysteresis differ mainly in the amount of adsorbed oxygen, the methoxy species and a carbonaceous species. Methoxy covers only a minor part of the catalytic surface reaching at most $20 \%$. Above $650 \mathrm{~K}$ the surface is largely adsorbate free.
\end{abstract}

\section{Introduction}

The catalytically important partial oxidation of methanol to formaldehyde over copper surfaces is linked to key mechanistic steps in several technologically processes as the methanol synthesis from "syngas" over $\mathrm{Cu} / \mathrm{ZnO}$ catalysts, and methanol steam reforming over $\mathrm{Al}_{2} \mathrm{O}_{3}$ supported $\mathrm{Cu} / \mathrm{ZnO} .^{1-6}$ Although high formaldehyde yields can be obtained using copper as catalyst, silver is still mainly used in industry.

Low pressure single crystal studies focussed on characterizing the role of methoxy and formate intermediates during the catalytic reaction. ${ }^{7-16}$ Different in situ techniques were applied in order to identify the active surface phases on polycrystalline $\mathrm{Cu}$ at higher pressure (mbar range). ${ }^{17-26}$ $\mathrm{Cu}(110)$ surfaces were investigated with temperatureprogrammed desorption (TPD), molecular beam techniques, low energy electron diffraction (LEED), x-ray photoelectron spectroscopy (XPS) and scanning tunnelling microscopy (STM). ${ }^{7,8,10-12,15,27-30}$ These techniques were typically applied under non-stationary conditions using sequential dosing and temperature-programmed experi- ments. Despite the characterization of ordered adlayers of reactive intermediates, the $(5 \times 2)$-methoxy and a $\mathrm{c}(2 \times 2)$ with STM and LEED, it remained unclear to what extent these structures really determine the reactivity of the $\mathrm{Cu}(110)$ surface. ${ }^{10-12,27-29}$ Furthermore, the assignment of the $\mathrm{c}(2 \mathrm{x} 2)$ to an adsorbate, i. e. the question whether it is a methoxy or a formate structure has been discussed controversially in the literature..$^{12,27,30-33}$ In a recent study of the stationary reaction kinetics on $\mathrm{Cu}(110)$ we showed that below $10^{-5}$ mbar range a pronounced low temperature reaction peak occurs between 400 and $500 \mathrm{~K}$. A second about equally high reactivity maximum occurs at $\mathrm{T}>800 \mathrm{~K}$. In the whole temperature regime the $\mathrm{CO}_{2}$ formation rate is very low, about 100 times smaller than the formaldehyde production rate. A rate hysteresis is found upon cyclic temperature variation associated with different adsorbate coverages on the two branches. ${ }^{34}$

The aim of the present in situ XPS study was to characterize and quantify the adsorbate layer on $\mathrm{Cu}(110)$ surface during stationary reaction conditions in order to relate the different adsorbates and ordered overlayers to the reactivity of the $\mathrm{Cu}(110)$ surface. 


\section{Experimental}

The experiments were performed at the undulator beamline U49/2-PGM1 at the synchrotron radiation facility BESSY in Berlin in a specially designed differentially pumped XPS system. In this setup X-rays are admitted to the experimental cell through a $100 \mathrm{~nm}$ thick $\mathrm{SiN}_{\mathrm{x}}$ window, where they illuminate the sample surface. The emitted photoelectrons enter a differentially pumped electrostatic lens system and are focused on the entrance slit of a standard electron energy analyser, where high vacuum conditions are maintained by a further pumping stage. The setup allows tuning the total pressure in the reaction cell between $10^{-7}$ mbar and 1 mbar. The reaction products were monitored with the help of a differentially pumped quadrupole mass spectrometer (QMS). In agreement with our recent experiments ${ }^{35}$ formaldehyde is always the major product. The $\mathrm{CO}_{2}$ formation rate is always $\sim 100$ times lower than the formaldehyde production. In this study, the cracking patterns of the different gases of importance were not recorded and the QMS signal intensity was not calibrated to a true particle flux as in ref. ${ }^{35}$, but the intensity of mass 30 , indicative for formaldehyde in the gas phase, was monitored applying identical measurement conditions so that the formaldehyde production rate within the performed experiments can be compared relatively on a scale of arbitrary units.

The sample temperature was varied with the help of an infrared laser heating system in the range between $300 \mathrm{~K}$ and $800 \mathrm{~K}$. Typical heating ramps of $5 \mathrm{~K} / \mathrm{min}$ were used. A $\mathrm{Cu}(110)$ single crystal was used as catalyst. It was mounted onto a temperature-controlled sample stage in the experimental cell. The partial pressures were adjusted using leak valves.

Since the UHV system was also operated as a flow reactor up to a pressure of 1 mbar only a base pressure of $10^{-8}$ mbar was reached typically, because the system was not baked between high pressure applications. Therefore, water from the chamber walls as the main residual gas component prevented a lower base pressure. A clean $\mathrm{Cu}(110)$ surface was obtained by sputtering and annealing to $870 \mathrm{~K}$. The surface could be kept C-free applying $\mathrm{p}\left(\mathrm{O}_{2}\right)$ $\geq 10^{-7}$ mbar at $\mathrm{T}>470 \mathrm{~K}$. In order to calibrate the adsorbate coverage the $\mathrm{Cu}$ surface was exposed to oxygen at $\mathrm{T}>520$ $\mathrm{K}$. The oxygen pressure was increased until the $\mathrm{O} 1 \mathrm{~s}$ intensity saturated at a typical pressure up to $\mathrm{p}\left(\mathrm{O}_{2}\right) \sim 5 \times 10^{-7}$ mbar. The dramatic drop of the $\mathrm{O}$-sticking coefficient when increasing the O-coverage from $0.5 \mathrm{ML}$ of the $\mathrm{O}-(2 \times 1)$ adlayer to the $0.67 \mathrm{ML}$ of the $\mathrm{O}-\mathrm{c}(6 \mathrm{x} 2)$ adlayer should result in the observed oxygen saturation effect. ${ }^{36}$ Therefore, we use the $\mathrm{O} 1 \mathrm{~s}$ saturation intensity level as the reference for $0.5 \mathrm{ML}$. The reproducibility was tested by following the $\mathrm{O} 1 \mathrm{~s}: \mathrm{Cu} 3 \mathrm{p}$ intensity ratio obtained in different calibration experiments. This ratio stayed constant within an error of $17 \%$. We want to point out that we cannot calculate a dosage, because the adjusted oxygen pressure fed a clean-off reaction on the $\mathrm{Cu}(110)$ surface of unknown rate.
The $\mathrm{C} 1 \mathrm{~s}$ spectra were calibrated by making use of the fact that formate and methoxy contain both, $\mathrm{C}$ and $\mathrm{O}$ atoms. Assuming that the photoelectron yield per $\mathrm{O}$ atom in the corresponding molecule equals the one of $\mathrm{O}_{\mathrm{ad}}$, the coverage of formate and methoxy was calculated by comparing the $\mathrm{O} 1 \mathrm{~s}$ peak intensities. Finally, referring to the measured $\mathrm{C} 1 \mathrm{~s}$ intensity to this calibration led to a proportionality of the $\mathrm{C} 1 \mathrm{~s}$ intensity and the corresponding coverage of $\mathrm{C}$ containing molecules, which was also used to calculate the coverage of the (O-free) $\mathrm{CH}_{\mathrm{x}}$ species evidenced on the $\mathrm{Cu}$ surface. This calibration is accurate within $\sim 20 \%$ as evidenced by comparing the results of different measurements. A systematical error due to eventual photoelectron diffraction effects cannot be excluded, but seems to be small, because - as will be seen further below - applying the described analysis to an inactive, fully adsorbate covered surface always yielded a total coverage of $\sim 1 \mathrm{ML}$. The C $1 \mathrm{~s}$ and $\mathrm{O} 1 \mathrm{~s}$ peak shapes were fitted by Doniach Sunjic functions. For $\mathrm{O} 1 \mathrm{~s}$ a Lorentzian width of $0.1 \mathrm{eV}$ and an asymmetry of 0.12 , for the $\mathrm{C} 1 \mathrm{~s}$ peak a Lorentzian width of $0.1 \mathrm{eV}$ and an asymmetry of 0.1 were used. The energy resolution of the experiment was $\sim 0.30 \mathrm{eV}$ at a photon energy of $465 \mathrm{eV}$ (used for the detection of $\mathrm{C} 1 \mathrm{~s}$ ) and $0.45 \mathrm{eV}$ at a photon energy of $710 \mathrm{eV}$ (used for the detection of $\mathrm{O} 1 \mathrm{~s})$.

Apart from the already discussed adsorbates a small amount of $\mathrm{Si}$ and $\mathrm{S}$ accumulated on the $\mathrm{Cu}(110)$ surface within a day or two during reaction conditions, visible by a Si $2 p$ and a S $2 p$ intensity just above detection limit. Parallel to the occurrence of the $\mathrm{Si} 2 \mathrm{p}$ peak an O 1s component at 531.0-531.8 eV binding energy was distinguishable in the spectra and could be fitted as a separate component. The corresponding coverage was determined by using the above outlined $\mathrm{O} 1 \mathrm{~s}$ calibration. We attribute the Si $2 \mathrm{p}$ and the corresponding $\mathrm{O} 1 \mathrm{~s}$ component to a SiOx contamination, which fits well to the determined $\mathrm{O} 1 \mathrm{~s}$ binding energy. ${ }^{37,38}$ The $\mathrm{SiO}_{\mathrm{x}}$ and the sulfur contamination were readily removed by sputtering every one or two days. The SiOx coverage never exceeded $0.08 \mathrm{ML}$. On the time scale of the experiments ( $\leq 3$ hours) the SiOx coverage remained constant. It is still unclear, where the Si contamination resulted from. Eventual segregation from the bulk of the $\mathrm{Cu}$ sample is a possible process. On the other hand, it has been found that the Si contamination increased dramatically when the total pressure was raised into the mbar range. Whether the pressure increase enhanced segregation or initiated Si mass transport through the gas phase could not be clarified. 


\section{Results}

\subsection{Identification of adsorbates in XPS}

\subsubsection{Oxygen adsorption}

Figure 1 shows the $\mathrm{O} 1 \mathrm{~s}$ calibration spectra for 0.5 ML oxygen coverage generated by exposing the $\mathrm{Cu}(110)$ sample to $\mathrm{p}\left(\mathrm{O}_{2}\right)=5 \times 10^{-7} \mathrm{mbar}$ at $\mathrm{T}=520 \mathrm{~K}$ and $770 \mathrm{~K}$. Each O 1s spectrum consists of two components, the main component, $\mathrm{O}_{\mathrm{ad} \_a}$, at $529.6 \mathrm{eV}$ and a smaller one, $\mathrm{O}_{\mathrm{ad} \_ \text {b }}$, at $528.9 \mathrm{eV}$ binding energy. $\mathrm{O} 1 \mathrm{~s}$ spectra at different temperatures reveal that the low binding energy component increases at higher temperature at the expense of the high binding energy species. The existence of the described components is evident when comparing the original data as visible in the upper panel of Fig. 1 . We assign the $\mathrm{O}_{\mathrm{ad} \_a}$ component to $\mathrm{O}$-atoms inside the $(2 \times 1)-\mathrm{O}$ adlayer, where they are bonded to two $\mathrm{Cu}$ atoms in the [001]-oriented $\mathrm{O}$ $\mathrm{Cu}-\mathrm{O}$ chains of the added row reconstruction. The $\mathrm{O}_{\mathrm{ad}} \mathrm{b}$ species might be associated with oxygen at defect sites, a disordered oxygen phase or with differently coordinated oxygen atoms in the (2x1)-O layer as it is the case for oxygen at the perimeter of the $(2 \times 1)-O$ islands. The finding that the intensity of the $\mathrm{O}_{\mathrm{ad} \_\mathrm{b}}$ species increases with temperature supports the latter possibilities (see below).

The assignment of different $\mathrm{O} 1 \mathrm{~s}$ binding energies to different oxygen species is still controversial in the literature. Bluhm et al. found in in situ XPS experiments at $\approx 1$ mbar two $\mathrm{O} 1 \mathrm{~s}$ states on polycrystalline $\mathrm{Cu}$, one at 532.0 $\mathrm{eV}$ and a second one at $530.4 \mathrm{eV} .^{25}$ Based on a depthprofiling experiment by variation of the photon energy they assigned the lower-lying oxygen state to subsurface oxygen. In an similar XPS study Buktiyarov et al. attributed the state at $529.8 \mathrm{eV}$ to chemisorbed oxygen and the peak at $531.2 \mathrm{eV}$ to a $\mathrm{Cu}$ suboxide. ${ }^{23,24}$ The term suboxide refers to the $\mathrm{Cu} / \mathrm{O}$ stochiometry and thus comprises subsurface oxygen. Due to the smallness of the signal intensity of the $\mathrm{O}_{a d} \mathrm{~b}$ component found in our experiment, we did not attempt to analyze its intensity change with varying photon energy.

\subsubsection{Reaction intermediates and characterization in XPS}

In the partial oxidation of methanol over copper a methoxy, $\mathrm{CH}_{3} \mathrm{O}_{\mathrm{ad}}$, and a formate intermediate, $\mathrm{HCOO}_{\mathrm{ad}}$, have been identified. Coadsorption of methanol and oxygen at $300 \mathrm{~K}$ and $10^{-7}$ mbar was found to lead to a $(5 \times 2)$ ordered ad-structure of methoxy on $\mathrm{Cu}(110) .^{9,28,34}$ Depending on the mixing ratio and on the adsorption time either a pure $(5 \times 2)$ pattern or a $(5 \times 2)$ layer coexisting with an $(2 \times 1)-O$ structure develops. Increasing the total pressure to $10^{-5}$ mbar causes the transformation into a $\mathrm{c}(2 \times 2)$ structure. One aim of this study was to characterize the adsorbate layer under co-dosing conditions, in order to decide the lasting

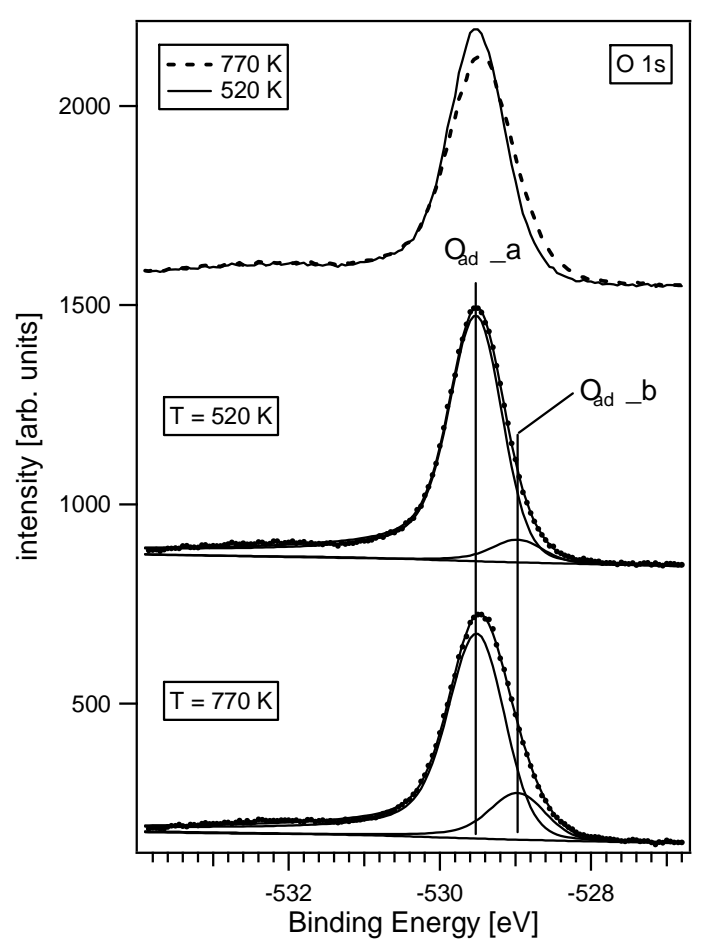

Fig. 1: Characterization of the oxygen species under reaction conditions by in situ photoelectron spectroscopy of the $\mathrm{O} 1 \mathrm{~s}$ core level. Top: $\mathrm{O} 1 \mathrm{~s}$ spectra obtained by $\mathrm{O}_{2}$ adsorption at $\mathrm{T}=520 \mathrm{~K}$ and $\mathrm{T}=$ $770 \mathrm{~K}$ with $\mathrm{p}\left(\mathrm{O}_{2}\right)=5 \times 10^{-7}$ mbar. Middle and bottom: $\mathrm{O} 1 \mathrm{~s}$ peak fits of the top spectra containing an $\mathrm{O}_{\mathrm{ad}}$ a component at $529.6 \mathrm{eV}$ and a smaller one, $\mathrm{O}_{\text {ad_b }}$, at $528.9 \mathrm{eV}$.

debate, whether the $\mathrm{c}(2 \times 2)$ is due to a formate or a methoxy species. ${ }^{12,27,30-32}$

The two lower panels a) and b) of Fig. 2 show the $O$ 1s and $\mathrm{C}$ 1s spectra obtained under stationary conditions close to room temperature, where no formaldehyde production occurs. (A reaction rate is detectable at $\mathrm{T} \geq 390$ $\mathrm{K})$. Two different methanol partial pressures $\mathrm{p}\left(\mathrm{CH}_{3} \mathrm{OH}\right)$, at $5 \times 10^{-6}$ mbar and $2 \times 10^{-6}$ mbar were applied, keeping the mixing ratio (MR) $\mathrm{p}\left(\mathrm{O}_{2}\right): \mathrm{p}\left(\mathrm{CH}_{3} \mathrm{OH}\right)$ constant at $\sim 0.3: 1$. Apparently different adsorption species are dominant on the surface depending on the total pressure. Formate, methoxy and $\mathrm{O}_{\mathrm{ad}}$ species as well as two $\mathrm{C}$-species which could not be assigned to any of the known intermediates can be identified. We attribute these $\mathrm{C}$-species to $\mathrm{CH}_{\mathrm{x}}(\mathrm{x}=0-3)$ adsorbates, because their corresponding $\mathrm{C} 1 \mathrm{~s}$ intensity does not correlate to any of the observed $\mathrm{O} 1 \mathrm{~s}$ components and because of the fact that the corresponding $\mathrm{C} 1 \mathrm{~s}$ components can even be found on the surface while almost no $\mathrm{O} 1 \mathrm{~s}$ intensity is recorded. In the following, we will call them $\mathrm{CH}_{\mathrm{x} \text { a }}$ and $\mathrm{CH}_{\mathrm{x} \mathrm{b}}$. They may be formed as side products of the reaction but they might also comprise contaminants originating from the residual gas. tThe combined coverage of these two C-species could be held below $0.5 \mathrm{ML}$ even on the non-reacting surface. At $320 \mathrm{~K}, \mathrm{p}\left(\mathrm{CH}_{3} \mathrm{OH}\right)=2 \times 10^{-6}$ mbar and a $\mathrm{MR}$ of $\mathrm{p}\left(\mathrm{O}_{2}\right): \mathrm{p}\left(\mathrm{CH}_{3} \mathrm{OH}\right) \sim 0.3: 1$, a mixture of 

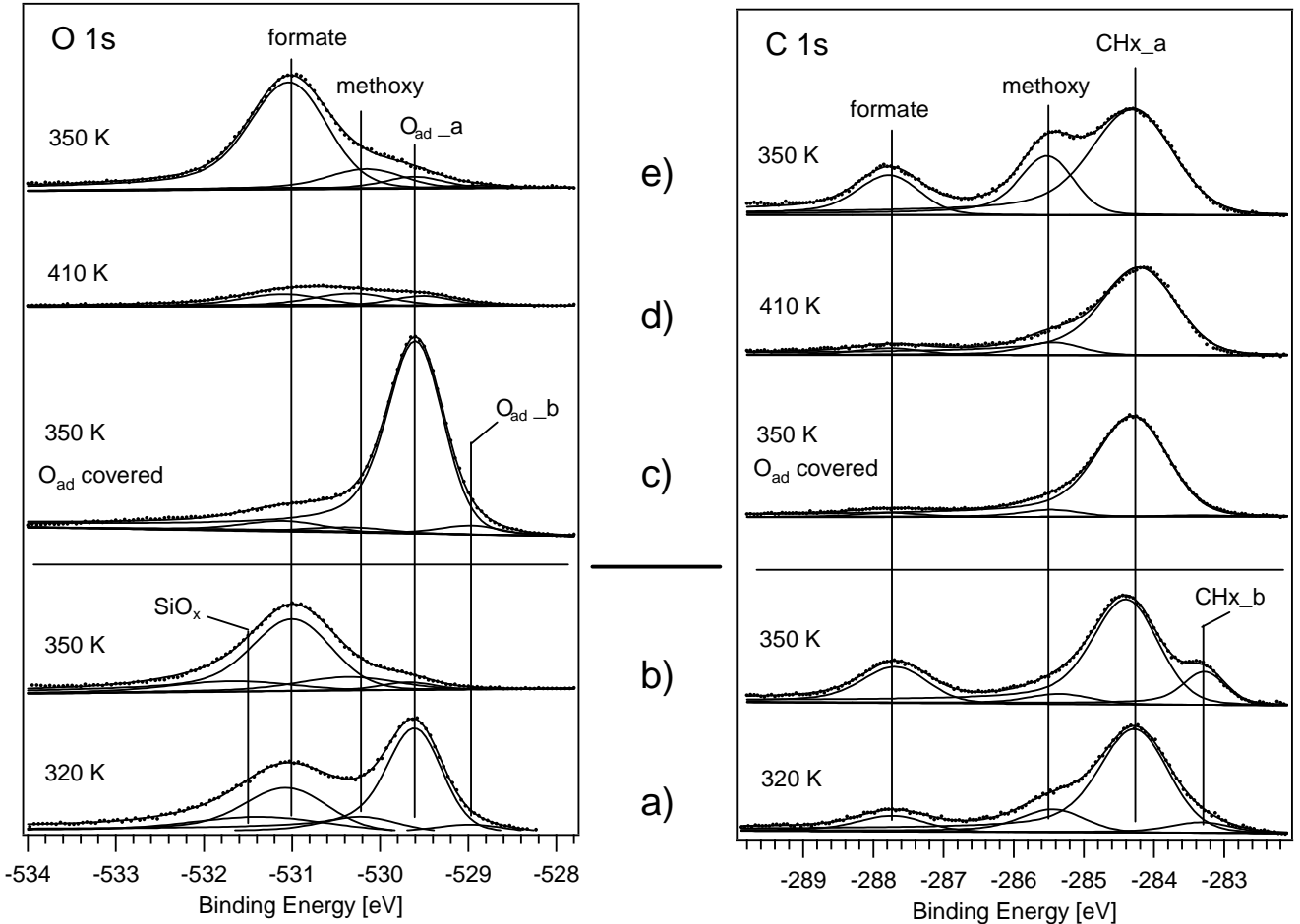

Fig. 2:Characterization of the adsorbate species on $\mathrm{Cu}(110)$ by in situ photoelectron spectroscopy of the $\mathrm{O} 1 \mathrm{~s}$ and $\mathrm{C}$ 1s core levels. Spectra (a) and (b) represent a stationary state of the surface. Spectra $(c-e)$ were recorded while the reaction conditions were varied and therefore these spectra are transients. The separation into two sets of experiments is marked by a horizontal bar in the figure.

a,b) Effect of total pressure on the adsorbate distribution under stationary reaction conditions at low temperature. A fixed $\mathrm{MR}=\mathrm{p}\left(\mathrm{O}_{2}\right): \mathrm{p}\left(\mathrm{CH}_{3} \mathrm{OH}\right)$ $\sim$ 0.3:1was used: a) $\mathrm{T}=320 \mathrm{~K}, \quad \mathrm{p}\left(\mathrm{CH}_{3} \mathrm{OH}\right)=2 \times 10^{-6}$ mbar b) $\mathrm{T}=350 \quad \mathrm{~K}, \quad \mathrm{p}\left(\mathrm{CH}_{3} \mathrm{OH}\right)=5 \times 10^{-6} \quad \mathrm{mbar}$. c-e) Development of the adsorbate distribution of an $\mathrm{O}_{\text {ad }}$ covered $\mathrm{Cu}(110)$ surface in a methanol rich gas atmosphere with $\mathrm{p}\left(\mathrm{CH}_{3} \mathrm{OH}\right)=1.4 \times 10^{-6}$ mbar and $\mathrm{MR}=\mathrm{p}\left(\mathrm{O}_{2}\right): \mathrm{p}\left(\mathrm{CH}_{3} \mathrm{OH}\right)=0.14: 1$ before and after short annealing to $450 \mathrm{~K}: \mathrm{c}$ ) at $350 \mathrm{~K}$ before annealing the $\mathrm{O}_{\mathrm{ad}}$ covered $\mathrm{Cu}(110)$ surface, (d) at $\mathrm{T}=410 \mathrm{~K}$ during cooling down after annealing and (e) during cooling down at $\mathrm{T}=350 \mathrm{~K}$.

Table 1: XPS binding energies (BE) for $\mathrm{O}_{\mathrm{ad}}$, formate and methoxy found on $\mathrm{Cu}(110)$.

\begin{tabular}{|c|c|c|c|c|c|c|}
\hline & \multicolumn{2}{|c|}{$\begin{array}{l}\text { formate: } \\
\mathrm{BE}[\mathrm{eV}]\end{array}$} & \multicolumn{2}{|c|}{$\begin{array}{l}\text { methoxy } \\
\mathrm{BE}[\mathrm{eV}]\end{array}$} & \multirow{2}{*}{$\begin{array}{c}\mathrm{O}_{\mathrm{ad}:} \\
\mathrm{BE}[\mathrm{eV}] \\
\mathrm{O} 1 \mathrm{~s}\end{array}$} & \multirow[t]{2}{*}{ Ref. } \\
\hline & $\mathrm{O} 1 \mathrm{~s}$ & C 1s & $\mathrm{O} 1 \mathrm{~s}$ & C 1s & & \\
\hline $\mathrm{Cu}(110)$ & & & 530.8 & 286.2 & $530.0( \pm 0.2)$ & 47 \\
\hline $\mathrm{Cu}(110)$ & 531.6 & 288 & 530.9 & 285.5 & 529.8 & 8 \\
\hline $\mathrm{Cu}(110)$ & 531.4 & 288.1 & & & 530 & 48 \\
\hline $\mathrm{Cu}(110)$ & 530.4 & 287.9 & & & $\begin{array}{l}\text { 530.7: O- }(2 \times 1) \\
529.5: \text { O-c }(6 \times 2)\end{array}$ & 49 \\
\hline $\mathrm{Cu}$ (poly) & 531.5 & 287.7 & 530.1 & 285.2 & 529.7 & 23 \\
\hline $\mathrm{Cu}(110)$ & 531.0 & 287.7 & 530.2 & 285.4 & 529.6 (a), 528.9 (b) & This study* \\
\hline
\end{tabular}

\footnotetext{
* In addition, two $\mathrm{CH}_{\mathrm{x}}(\mathrm{X}=0-3)$ species were found: $\mathrm{CH}_{\mathrm{x} \_\mathrm{a}}$ at $284.2 \mathrm{eV}$ and $\mathrm{CH}_{\mathrm{x} \_\mathrm{b}}$ at $283.3 \mathrm{eV}$.
} 
$\mathrm{O}_{\mathrm{ad}}$, formate and methoxy adsorbates is present on the surface as demonstrated by Fig.2a. The determined binding energies of the different adsorbate species are summarized in Table 1, where literature data are included for comparison. As evidenced by the reaction rate the $\mathrm{Cu}(110)$ surface of Fig. 2a is not reactive.

Upon increasing $\mathrm{p}\left(\mathrm{CH}_{3} \mathrm{OH}\right)$ to $5 \times 10^{-6}$ mbar with a fixed $\mathrm{MR}=\mathrm{p}\left(\mathrm{O}_{2}\right): \mathrm{p}\left(\mathrm{CH}_{3} \mathrm{OH}\right)=0.3: 1$ at $\mathrm{T}=350 \mathrm{~K}$ the formate coverage increased on cost of methoxy as shown by Fig. 2b. At $350 \mathrm{~K}$ the $\mathrm{Cu}(110)$ surface is still inactive as judged from the reaction rate. Since LEED shows that a $\mathrm{c}(2 \times 2)$ is generated under these conditions this $\mathrm{c}(2 \times 2)$ evidently represents an ordered formate phase. ${ }^{34}$ This assignment agrees with refs. ${ }^{31-33,39}$ and is in contradiction to the conclusions of refs. ${ }^{12,27}$, where a methoxy species has been proposed as building unit of the $\mathrm{c}(2 \times 2)$. The reason for this discrepancy can be sought in the fact that STM probes a small area and therefore STM images showing a methoxy phase with $\mathrm{c}(2 \times 2)$ symmetry might represent a minority phase. Furthermore, the contradictive data in the literature might originate from the sensitivity to the total pressure which determines whether a $\mathrm{c}(2 \times 2)$-formate or a $(5 \times 2)$ methoxy layer is formed on the $\mathrm{Cu}(110)$ surface. $\mathrm{A} \mathrm{c}(2 \times 2)-$ adlayer was observed during co-dosing only at $\mathrm{p}>10^{-6}$ mbar, with the same gas mixing ratio but at lower total pressure a $(5 \times 2)$ overlayer develops. ${ }^{34}$

In order to improve the quality of the $\mathrm{O} 1 \mathrm{~s}$ and $\mathrm{C} 1 \mathrm{~s}$ fits a high methoxy coverage was required since the corresponding peak usually was masked by the $\mathrm{O}_{\mathrm{ad} \_a}$ and the $\mathrm{CH}_{\mathrm{x} \_\mathrm{a}}$ peak respectively. Therefore, the following procedure was used characterized by the transient XPS data in Fig. 2c-e. An oxygen pre-covered surface was annealed to $450 \mathrm{~K}$ and subsequently cooled down in a methanol rich atmosphere $\left(\mathrm{p}\left(\mathrm{CH}_{3} \mathrm{OH}\right)=1.4 \times 10^{-6} \mathrm{mbar}\right.$ and a $\mathrm{MR}=$ 0.14:1). The corresponding $\mathrm{C} 1 \mathrm{~s}$ and $\mathrm{O} 1 \mathrm{~s}$ spectra reproduced in the top three panels of Fig.2 show that initially the $\mathrm{O}_{\mathrm{ad}}$ layer (Fig. 2c) was reactively removed by methanol (Fig. 2d). After some time during cooling down, a significant amount of formate and methoxy species developed resulting in well separated peaks at $350 \mathrm{~K}$ as demonstrated by the corresponding $\mathrm{C} 1 \mathrm{~s}$ and $\mathrm{O} 1 \mathrm{~s}$ spectra in Fig. 2e. The different reaction intermediates on the surface are thus well characterized.

\subsection{Surface reactivity and adsorbate coverages}

Figure 3 displays the formaldehyde production rate (top panel) together with the adsorbate coverages (lower two panels) as determined from in situ XPS during a TPR experiment. A methanol partial pressure of $\mathrm{p}\left(\mathrm{CH}_{3} \mathrm{OH}\right)=$ $5 \times 10^{-6}$ mbar was chosen with a mixing ratio $\mathrm{MR}=0.6: 1$. Besides the adsorbates $\mathrm{O}_{\mathrm{ad}}$, methoxy and formate also the species $\mathrm{CH}_{\mathrm{x} \_\mathrm{a}}, \mathrm{CH}_{\mathrm{x} \_\mathrm{b}}$ and $\mathrm{SiO}_{\mathrm{x}}$. were monitored. The coverages in Figure 3 are absolute coverages of molecules per surface atom calculated in monolayers (ML), where $1 \mathrm{ML}$ corresponds to the number of $\mathrm{Cu}$ surface atoms on the nonreconstructed $\mathrm{Cu}(110)$ plane. The surface area covered by an adsorbate differs from the coverage, since the adsorbate layers have different densities. The $(5 \times 2)$-methoxy layer is thought to have an adsorbate coverage of $0.4 \mathrm{ML},{ }^{10}$ whereas the $(2 \times 1)-O$ layer ideally hosts an oxygen coverage of $0.5 \mathrm{ML} .^{40,41}$ Similarly, the $\mathrm{c}(2 \mathrm{x} 2)$-formate also corresponds to $0.5 \mathrm{ML}^{42}$

The fact that a total coverage of slightly below $1 \mathrm{ML}$ is reached requires that at least some adsorbates must coadsorb in the same area, i. e. they have to occupy different adsorption sites. One can suspect that some of the $\mathrm{CH}_{\mathrm{x}}$ species adsorb inside the ordered oxygen and methoxy phases. Since each formate molecule is bonded to two $\mathrm{Cu}$ surface atoms coadsorption within the formate covered area appears unlikely. If we assume that irrespective of the degree of ordering the adsorbate density remains approximately the same, we can calculate the fraction of the surface, which is covered by the different ad-species from the known densities of the ordered overlayers. The resulting diagram is displayed in the lowest panel of Figure 3.

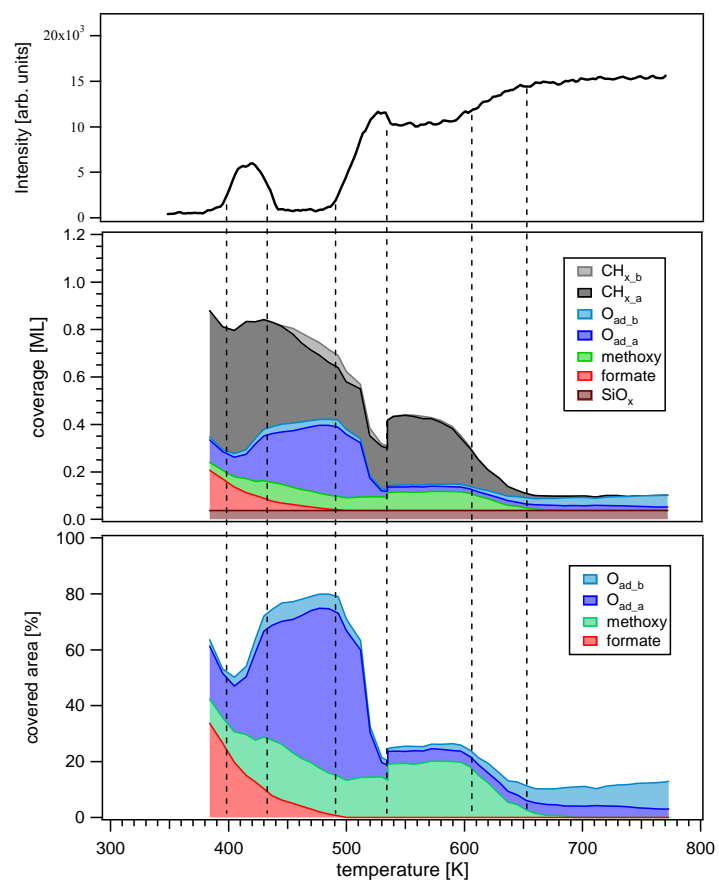

Fig. 3: Relation between adsorbate coverages and reactivity during heating up. Top: formaldehyde production rate. Middle: adsorbate coverages in ML. Bottom: fraction of the surface covered by the different adsorbates (see text).

Experimental conditions: $\mathrm{p}\left(\mathrm{CH}_{3} \mathrm{OH}\right)=5 \times 10^{-6}$ mbar, $\mathrm{MR}=$ $\mathrm{p}\left(\mathrm{O}_{2}\right): \mathrm{p}\left(\mathrm{CH}_{3} \mathrm{OH}\right)=0.6: 1$. A heating rate of $5 \mathrm{~K} / \mathrm{min}$ was used.

A striking fact of Figure 3 is that even with methanol being in excess almost no methoxy is found on the unreactive surface present below $390 \mathrm{~K}$. Instead, the subsequent oxidation product, formate, is the dominant adsorbate species. A similar situation was already reached applying even a more methanol rich gas mixture with a $\mathrm{MR}=0.3: 1$ at a methanol pressure of $5 \times 10^{-6}$ mbar as demonstrated in Fig. 2a. Upon ignition of the reaction at $\approx 400 \mathrm{~K}$ the formate concentration on the surface drops, and the formaldehyde 
production rate accelerates to its low temperature peak. One can suspect that it is the liberation of vacant sites provided by formate decomposition which is responsible for the rise in catalytic activity. At slightly higher temperature some of the free surface is covered by methoxy but most of it is filled by $\mathrm{O}_{a d}$ and the reaction is blocked. Temperatures above $500 \mathrm{~K}$ are required to ignite again the reaction.

The reason why the surface becomes deactivated in the intermediate temperature range of $430-490 \mathrm{~K}$ is that the surface is filled with chemisorbed oxygen, which at high coverage inhibits the reaction. At these temperatures no formate is present any more on the surface, whereas the methoxy species is detectable up to $650 \mathrm{~K}$. Over the relatively broad temperature range from $410-650 \mathrm{~K}$ methoxy and $\mathrm{O}_{\mathrm{ad}}$ coexist. Above $650 \mathrm{~K}$ only oxygen is present on the surface, but now the $\mathrm{O}_{\mathrm{ad} \_\mathrm{b}}$ species dominates.

One particular feature visible in Fig. 3 should be explained, which originates from an experimental artefact. At $530 \mathrm{~K}$ a drop in the formaldehyde production takes place accompanied by an increase of $\mathrm{C}$ species. At this temperature the ramp was stopped for $40 \mathrm{~min}$ in order to wait for the following injection at the beamline. During this time the oxygen partial pressure dropped slightly $(<10 \%)$, which resulted in an increase of the $\mathrm{CH}_{\mathrm{x}_{-} \mathrm{a}}$ and $\mathrm{CH}_{\mathrm{x} \_\mathrm{b}}$ species.

The above results can be summarized as follows:

1) At $300 \mathrm{~K}$ the $\mathrm{Cu}(110)$ surface is inactive and completely covered by adsorbates.

2) Formate is the most prominent carbon containing adsorbate of methanol oxidation on this inactive surface.

3) Ignition of the reaction at $\approx 400 \mathrm{~K}$ correlates with a decay of the formate concentration.

4) The deactivation of the surface between $430 \mathrm{~K}$ and $490 \mathrm{~K}$ is caused by surface poisoning with a high coverage of adsorbed oxygen.

5) The methoxy species always covers only a minor fraction of the surface. This species is detectable at temperatures between $\approx 410 \mathrm{~K}$ and $650 \mathrm{~K}$.

\subsection{Hysteresis Effects}

Figure 4 displays the coverages and the formaldehyde production rate during a temperature cycle under stationary reaction conditions. The associated LEED patterns determined in a separate experiment under similar conditions are included in the plot. As noted before in rate, Auger and PEEM intensity measurements a wide hysteresis exists in the reaction rates associated with a corresponding hysteresis in the adsorbate coverages. ${ }^{34}$ While the data in ref. $^{34}$ allowed no precise identification of the adsorbates now qualitative and quantitative information is available.

Qualitatively the course of the rate hysteresis remains similar to ref. ${ }^{34}$ which shows that the influence of the additional carbon species $\mathrm{CH}_{\mathrm{x}_{-} \mathrm{a}}$ and $\mathrm{CH}_{\mathrm{x}_{-} \mathrm{b}}$ is of minor importance. The main difference between the heating and the cooling branch is that the adsorbate coverage on the heating branch is much higher than on the cooling branch. In par- ticular, chemisorbed oxygen and the methoxy species reach a substantial coverage only during heating up. The amount of the formate species which dominates at low temperature does not exhibit a large difference between heating and cooling. When we take a look at the coverages in the dip of the reactivity during heating up, we see that a large oxygen coverage is present in this dip which does not exist on the reactive cooling branch. Apparently a large oxygen coverage has a poisonous effect on the reaction.

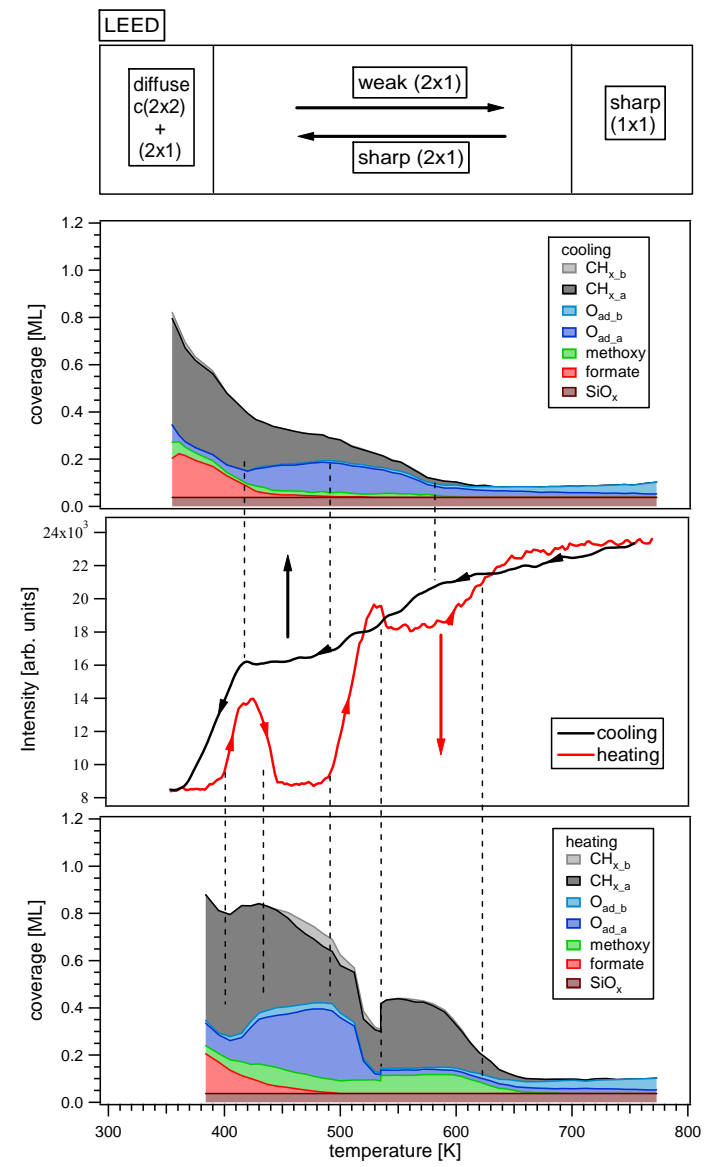

Fig. 4: Connection between the hysteresis in the reaction rate and the adsorbate coverage. The hysteresis in the formaldehyde production observed upon T-cycling is displayed in the third panel from top. The panels above and below represent the adsorbate coverages associated with the heating and cooling branch, respectively. The top panel summarizes the LEED observations during a T-cycle.

Experimental conditions: $\mathrm{p}\left(\mathrm{CH}_{3} \mathrm{OH}\right)=5 \times 10^{-6}$ mbar, $\mathrm{MR}=$ $\mathrm{p}\left(\mathrm{O}_{2}\right): \mathrm{p}\left(\mathrm{CH}_{3} \mathrm{OH}\right)=0.6: 1$. The heating and the cooling ramp were performed applying a constant temperature variation of $5 \mathrm{~K} / \mathrm{min}$.

LEED evidences a sharp $(2 \mathrm{x} 1)$ pattern during the cooling branch of the TPR experiment, while only weak (2x1) spots are visible during up-ramping. ${ }^{34}$ From the oxygen coverages one would intuitively just expect the opposite correlation, i.e. the sharp $(2 \times 1)$ pattern during heating 


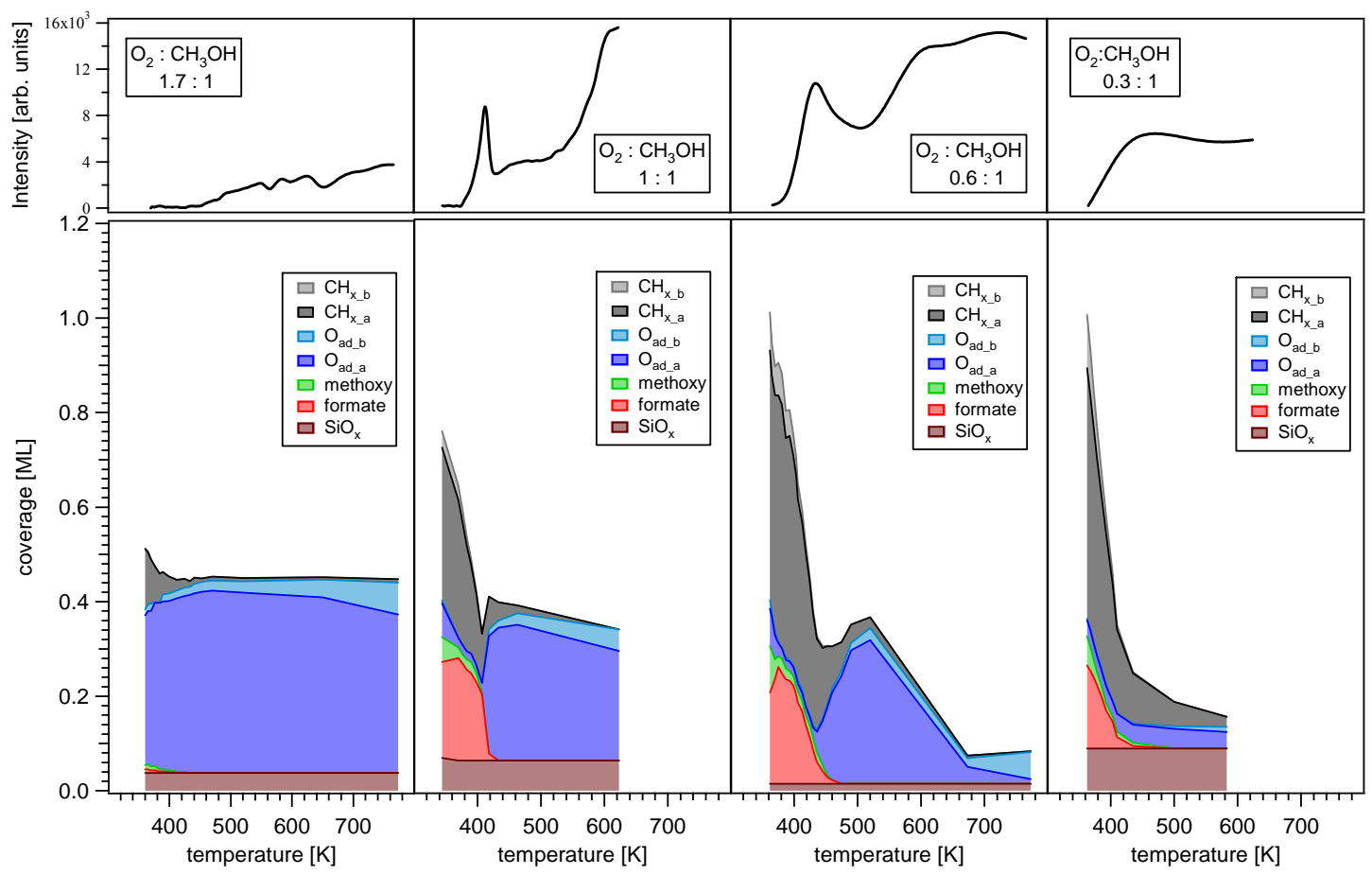

Fig. 5: Influence of the mixing ratio on the adsorbate coverages and reactivity of the surface. The top panel represents the formaldehyde production for different mixing ratios; the lower panel displays the adsorbate coverages on the cooling branch of the hysteresis. Note that a higher cooling rate of an estimated $100 \mathrm{~K} / \mathrm{min}$ at temperatures above $\sim 500 \mathrm{~K}$ was applied. Experimental conditions: $\mathrm{p}\left(\mathrm{CH}_{3} \mathrm{OH}\right)=5 \times 10^{-6} \mathrm{mbar}, \mathrm{MR}=$ $\mathrm{p}\left(\mathrm{O}_{2}\right): \mathrm{p}\left(\mathrm{CH}_{3} \mathrm{OH}\right)$ as indicated.

up. We therefore have to conclude that during heating chemisorbed oxygen is either mostly disordered or ordered in quite small O-(2x1) islands. During cooling the oxygen coverage is much smaller but the oxygen is well ordered in large $(2 \times 1)-O$ islands. We also note that at intermediate temperatures the oxygen species belonging to $\mathrm{O}_{\mathrm{ad}-\mathrm{b}}$ is nearly only present during heating up while this species is almost extinguished during cooling down. At first sight this is consistent with the different size of the oxygen islands during heating/cooling if we associate the $\mathrm{O}_{\text {ad-b }}$ species with oxygen at the perimeter of the $(2 \times 1)-O$ islands or a disordered oxygen phase.

In a separate experiment, we repeated the experiment of Fig. 4, with the cooling speed increased to roughly 100 $\mathrm{K} /$ min for temperatures above $\sim 500 \mathrm{~K}$. The distribution of coverages remained almost the same with the exception of $\mathrm{O}_{\mathrm{ad}}$, where the coverage between $490 \mathrm{~K}$ and $560 \mathrm{~K}$ was about twice as high as with the slow cooling. We attribute this to the fact that large $\mathrm{O}-(2 \mathrm{x} 1)$ islands develop at high temperature which contain only a relative small portion of active oxygen atoms at the perimeter and therefore survive as metastable structures during cooling down.

Figure 5 displays the coverages for all ad-species and the formaldehyde production rate during temperature down-ramping for varying ratios of $\mathrm{p}\left(\mathrm{O}_{2}\right): \mathrm{p}\left(\mathrm{CH}_{3} \mathrm{OH}\right)$. The methanol partial pressure in these experiments was kept fixed at $\mathrm{p}\left(\mathrm{CH}_{3} \mathrm{OH}\right)=5 \times 10^{-6}$ mbar while only the oxygen content was varied. A significantly higher cooling rate than $5 \mathrm{~K} / \mathrm{min}$ (up to $100 \mathrm{~K} / \mathrm{min}$ ) was applied at temperatures above $\sim 500 \mathrm{~K}$. To a certain degree the measured coverages in this part are therefore transient but qualitatively, the influence of the different ratios $\mathrm{p}\left(\mathrm{O}_{2}\right): \mathrm{p}\left(\mathrm{CH}_{3} \mathrm{OH}\right)$ is nevertheless well visible. Clearly, a high oxygen coverage correlates with a low catalytic activity but also a very low oxygen content causes a loss in activity so that a certain optimum mixing ratio exists which, according to Fig. 5 is around $\mathrm{p}\left(\mathrm{O}_{2}\right): \mathrm{p}\left(\mathrm{CH}_{3} \mathrm{OH}\right)=0.6: 1$. Furthermore, the decay of the activity at low temperature is, in all cases, accompanied by the development of formate on the surface. Even when the oxygen content is very high, at $\mathrm{p}\left(\mathrm{O}_{2}\right): \mathrm{p}\left(\mathrm{CH}_{3} \mathrm{OH}\right)=1.7: 1$ a tiny amount of formate can be observed at $380 \mathrm{~K}$.

Figure 6 displays the hysteresis in reaction rate and coverages for methanol-rich gas with a mixing ratio $\mathrm{p}\left(\mathrm{O}_{2}\right): \mathrm{p}\left(\mathrm{CH}_{3} \mathrm{OH}\right)=0.3: 1$. Again, between $800 \mathrm{~K}$ and 480 $\mathrm{K}$, temperature down-ramping was performed with a fast rate of $\approx 100 \mathrm{~K} / \mathrm{min}$. Therefore, the corresponding part of the curves does not represent a true steady state. Compared to the oxygen rich mixtures the oxygen coverage is now rather small and the amount of carbon species $\mathrm{CH}_{\mathrm{x}_{-} \mathrm{a}}$ and $\mathrm{CH}_{\mathrm{x}_{\mathrm{b}} \mathrm{b}}$ accordingly quite high. As before, we note a broad hysteresis but the low-T reactivity peak during heating up is now largely suppressed and the reactivity of the cooling branch is generally larger than on the heating branch. On the heating branch we observe a substantial amount of methoxy up to $600 \mathrm{~K}$, while this species is nearly completely absent on the cooling branch. The general trend is the same 


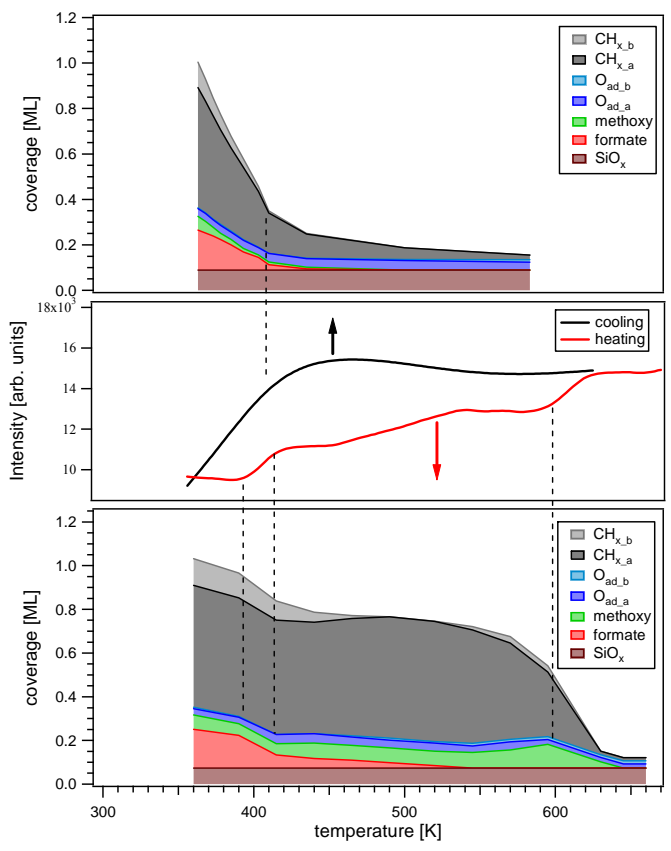

Fig. 6: Hysteresis with a methanol rich gas mixture. The formaldehyde production is displayed in the middle panel. The panels above and below represent the adsorbate coverages associated with the heating and cooling branch, respectively.

Experimental conditions: $\mathrm{p}\left(\mathrm{CH}_{3} \mathrm{OH}\right)=5 \times 10^{-6}$ mbar, $\mathrm{MR}=$ $\mathrm{p}\left(\mathrm{O}_{2}\right): \mathrm{p}\left(\mathrm{CH}_{3} \mathrm{OH}\right)=0.3: 1$. Heating rate during annealing: $5 \mathrm{~K} / \mathrm{min}$, during cooling: $\sim 100 \mathrm{~K} / \mathrm{min}$ for $\mathrm{T}>500 \mathrm{~K}$.

as before. We observe a broad hysteresis that is associated with different total coverages but the adsorbate now consists mostly of carbon containing species and very little oxygen.

For an oxygen rich gas mixture adsorbate coverages together with the reactivity are displayed in Fig. 7, showing a T-cycle for a methanol partial pressure of $5 \times 10^{-6} \mathrm{mbar}$ and a mixing ratio $\mathrm{p}\left(\mathrm{O}_{2}\right): \mathrm{p}\left(\mathrm{CH}_{3} \mathrm{OH}\right)=1: 1$. As expected, the oxygen coverage is now substantial on both branches of the T-cycle. As in the experiments displayed in Figs. 5 and 6, the cooling was performed at a higher rate. The broad hysteresis occurs associated with a different adsorbate distribution on the heating and cooling branch. Due to a slight increase of the oxygen partial pressure between heating and cooling, the oxygen coverage at the beginning of the cooling experiment is enlarged compared to the coverage at the end of the heating branch. This is probably the reason for the reduced reactivity during cooling. After formate decomposition ignites the surface reaction upon heating, a pronounced oxygen poisoning follows. As before, the methoxy species is only a minority species as long as formate is present. However, on the heating branch the methoxy species survives the formate becoming the only intermediate above $470 \mathrm{~K}$ where it is detectable up to $560 \mathrm{~K}$.

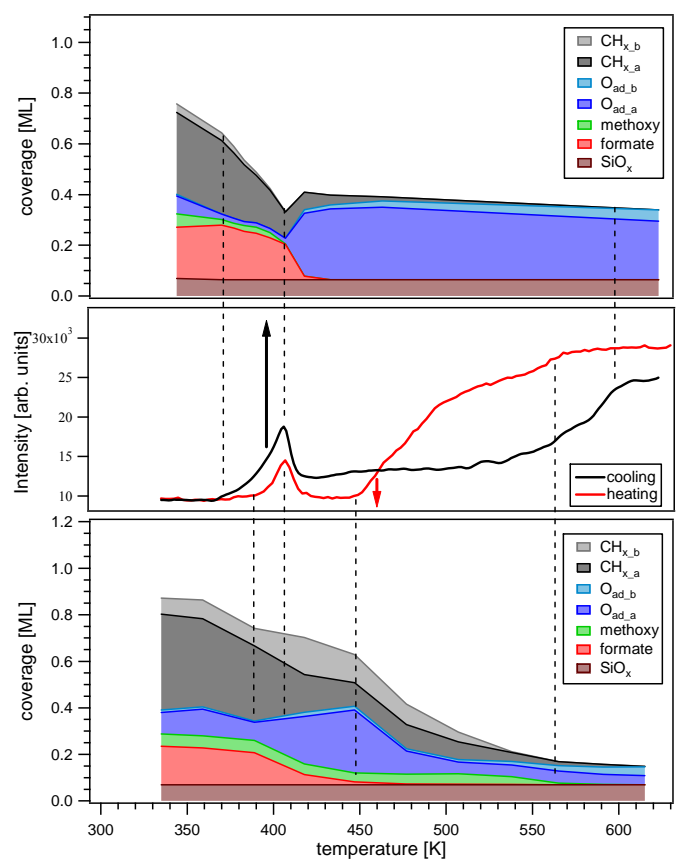

Fig. 7: Hysteresis with an oxygen rich gas mixture. The formaldehyde production is displayed in the middle panel. The panels above and below represent the adsorbate coverages associated with the heating and cooling branch, respectively.

Experimental conditions: $\mathrm{p}\left(\mathrm{CH}_{3} \mathrm{OH}\right)=5 \times 10^{-6}$ mbar, $\mathrm{MR}=$ $\mathrm{p}\left(\mathrm{O}_{2}\right): \mathrm{p}\left(\mathrm{CH}_{3} \mathrm{OH}\right)=1: 1$. Heating rate during annealing: $5 \mathrm{~K} / \mathrm{min}$, during cooling: $\sim 100 \mathrm{~K} / \mathrm{min}$ for $\mathrm{T}>500 \mathrm{~K}$.

\section{Results}

\section{1. Mechanism}

Two competing reaction channels to formaldehyde formation via $\mathrm{H}_{2}$ formation and without $\mathrm{H}_{2}$ production can be formulated

(1)

$$
4 \mathrm{CH}_{3} \mathrm{OH}+\mathrm{O}_{2} \rightarrow 4 \mathrm{CH}_{2} \mathrm{O}+2 \mathrm{H}_{2}+2 \mathrm{H}_{2} \mathrm{O} \text {, }
$$

$$
520 \mathrm{~K}<\mathrm{T}<750 \mathrm{~K}
$$

$$
2 \mathrm{CH}_{3} \mathrm{OH}+\mathrm{O}_{2} \rightarrow 2 \mathrm{CH}_{2} \mathrm{O}+2 \mathrm{H}_{2} \mathrm{O},
$$

$\mathrm{T}>750 \mathrm{~K}$

In order to account for the two experimentally determined intermediates, methoxy and formate, the following skeleton mechanism has been suggested, e.g. ${ }^{32}$ :

$$
\begin{aligned}
& \mathrm{CH}_{3} \mathrm{OH}_{\mathrm{ad}}+\mathrm{O}_{\mathrm{ad}} \rightarrow \mathrm{CH}_{3} \mathrm{O}_{\mathrm{ad}}+\mathrm{OH}_{\mathrm{ad}} \\
& \mathrm{CH}_{3} \mathrm{O}_{\mathrm{ad}} \rightarrow \mathrm{H}_{2} \mathrm{CO}_{\mathrm{ad}}+\mathrm{H}_{\mathrm{ad}} \rightarrow \mathrm{H}_{2} \mathrm{CO}+\mathrm{H}_{\mathrm{ad}}
\end{aligned}
$$

$$
\mathrm{CH}_{3} \mathrm{O}_{\mathrm{ad}}+\mathrm{O}_{\mathrm{ad}} \rightarrow \mathrm{HCOO}_{\mathrm{ad}}+2 \mathrm{H}_{\mathrm{ad}}
$$




$$
\begin{aligned}
& \mathrm{H}_{2} \mathrm{CO}_{\mathrm{ad}}+\mathrm{O}_{\mathrm{ad}} \rightarrow \mathrm{HCOO}_{\mathrm{ad}}+\mathrm{H}_{\mathrm{ad}} \\
& \mathrm{HCOO}_{\mathrm{ad}} \rightarrow \mathrm{CO}_{2}+\mathrm{H}_{\mathrm{ad}}
\end{aligned}
$$

Formate via reaction partway (R3b) is unlikely due to the low adsorption energy of $\mathrm{CH}_{2} \mathrm{O}$ which causes a practically immediate desorption of this species. Quantum chemical calculations yield a value of $\sim 0.63 \mathrm{eV} .{ }^{43}$ All hydrogen abstracting steps can in principle formulated as dehydrogenation or as oxidation through direct interaction with chemisorbed oxygen or an $\mathrm{OH}$ species. At low temperature $(\mathrm{T}<400 \mathrm{~K})$ the intermediates form two ordered overlayers, (5x2)-methoxy and a c (2x2) whose assignment has not been clear but which on the basis of the present results can clearly be attributed to formate. This assignment of the $\mathrm{c}(2 \times 2)$ phase to formate has been already discussed in section 3.1.2. The result was that the debate in the literature on whether this ordered adlayer represents a methoxy of formate species has been resolved.

The formate species dominates on the inactive surface at low $\mathrm{T}$ but the formate route plays only a minor role on the active surface under stationary conditions since it leads to the total oxidation product $\mathrm{CO}_{2}$ which in our experiments does not exceed $1 \%$ of the formaldehyde production rate. We propose that the formate species is produced at a low rate and decomposes at a very low rate. Because its decomposition to $\mathrm{CO}_{2}$ via $\mathrm{R} 4$ is switched off at low temperature it accumulates on the surface.

At higher temperature the methoxy pathway to formaldehyde production becomes dominant and we have to explain why this is the case. The equilibrium $\mathrm{CH}_{3} \mathrm{O}_{\mathrm{ad}}<=>$ $\mathrm{H}_{2} \mathrm{CO}_{\mathrm{ad}}+\mathrm{H}_{\mathrm{ad}}$ shifts to the product side when the product formaldehyde can leave the surface through desorption. Bowker et al. suggested that methoxy decomposition to formaldehyde can only take place on the free $\mathrm{Cu}$ surface. ${ }^{10,32}$ The observed hysteresis in total coverage, which is associated with a hysteresis of accumulated methoxy species supports in fact such an explanation. As a result a negative correlation between total coverage and catalytic activity is found in the XPS data.

The low rate of formate generation explains some of the seemingly contradictive results in the literature, whether or not formate is present on a catalytic $\mathrm{Cu}(110)$ surface. In order to accumulate formate on the $\mathrm{Cu}$ surface, either elevated pressures are required, which are usually avoided in UHV studies or the sample has to be left for a very long time in vacuum after dosing the gases until formate develops as reported by Carley et al.. ${ }^{8}$ As well our TPD experiments support the existence of a very slow formate generation under the conditions of our experiments. TPD spectra from a $\mathrm{c}(2 \times 2)$ layer showed a large $\mathrm{CO}_{2}$ peak as expected for adsorbed formate (see e.g. Ref. ${ }^{44}$ ). On the other hand, the $\mathrm{CO}_{2}$ peak obtained from a $(5 \times 2)$ methoxy layer was significantly lower but still substantial, which indicates formate formation either during the temperature ramp of the TPD experiment itself or during the time between the preparation of the adsorption layer and the analy- sis. The latter takes place at least to some degree, because the observed $\mathrm{CO}_{2}$ peak height varied with the waiting time between the preparation of the $(5 \times 2)$ adlayer and the TPD analysis. $^{45}$

Although the formate production rate is very low, it is responsible for the low temperature reactivity of the $\mathrm{Cu}(110)$ surface at experiments in the $10^{-5}$ mbar range, since the catalytic reactivity sets in when the temperature of formate decomposition at $\mathrm{T} \sim 400 \mathrm{~K}$ is passed as evidenced by the XPS data. If the formate decomposition rate is further increased by raising the temperature beyond $400 \mathrm{~K}$, the surface accumulates oxygen which poisons the surface and eventually completely suppresses the catalytic reaction.

\subsection{Role of oxygen}

The experiments in this paper and previous ones have demonstrated that high oxygen coverages inhibit the reaction. ${ }^{9,35,46}$ Even at coverages below that of the high coverage phases, i. e. at the $\theta_{\mathrm{O}}=0.5$ of a (2x1)- 0 structure the reactivity is already strongly reduced. A straightforward explanation was provided by STM experiments showing that only the terminal oxygen atoms of the $\mathrm{O}-\mathrm{Cu}-\mathrm{O}$ chains forming the $(2 \times 1)$-O are reactive towards adsorbed methanol. Upon reaction they convert the methanol into a methoxy species and the terminal $\mathrm{O}$-atom into $\mathrm{OH}$.

In the XPS experiments two $\mathrm{O} 1 \mathrm{~s}$ signals were seen. Species A can be attributed to oxygen in the $(2 \mathrm{x} 1)-\mathrm{O}$ phase. Species B was tentatively assigned either to disordered oxygen and oxygen at defects or chemisorbed oxygen at the perimeter of the $(2 \times 1)-O$ islands. Given that only the edge atoms are reactive a strict correlation should exist between the catalytic activity and the $\mathrm{O} 1 \mathrm{~s}$ signal of species $\mathrm{B}$ if species B was in fact due to oxygen at the perimeter of the (2x1)-O islands. At high temperature the data show in fact a certain correlation but at low temperature, i. e. below 500 $\mathrm{K}$ no such connection can be found (see e. g. Fig. 3). This observation does not necessarily rule out this assignment because other adsorbates such as formate or carbonaceous species surrounding the $(2 \times 1)-O$ islands might render edge oxygen atoms unreactive.

It has to be pointed out that oxygen poisoning can completely suppress the low temperature surface reactivity. In that case much higher temperatures are required to ignite the reaction again. Oxygen poisoning is very sensitive to the oxygen partial pressure in the feed as evidenced by XPS data. We conclude that at temperatures well above the onset of formate decomposition the oxygen adsorption rate is higher than the formate production rate, which leads to the observed increase of the oxygen coverage on the surface and to the poisoning of the catalytic reaction. We propose that this mechanism accounts for the absence of a low temperature reactivity at total pressures above $10^{-2}$ mbar.

In the low temperature reactivity window formate decomposition is balanced by formate production thus preventing oxygen poisoning. At high total pressure, this temperature window shifts to higher values while its 
temperature interval shrinks as observed experimentally. ${ }^{35}$ Therefore, at high pressure the $\mathrm{Cu}(110)$ surface is formate covered and the surface is non-reactive at temperatures below the onset of formate decomposition. Slightly above this temperature the surface becomes oxygen poisoned and turns unreactive again. Significantly higher temperatures are required to overcome the oxygen poisoning and to ignite the reaction.

A pressure gap in the partial oxidation of methanol over $\mathrm{Cu}(110)$ exists because the low temperature reactivity peak around $400-500 \mathrm{~K}$ vanishes as the total pressure is increased beyond $10^{-3}$ mbar. Furthermore, at low total pressure $\left(\mathrm{p}<10^{-3} \mathrm{mbar}\right)$ and low temperature the active state of the $\mathrm{Cu}(110)$ catalyst ris determined by the coverages of methoxy, formate, and oxygen species and eventually by the number of free $\mathrm{Cu}$ sites. On the other hand, when the total pressure is increased above $10^{-2}$ mbar, a reactive surface is obtained only when the poisoning through adsorbed oxygen is overcome. Under these "high pressure" conditions processes like oxide and suboxide formation play an important role and they will determine the reactivity of the surface while the reaction intermediates become less important..

\section{Conclusions}

From in situ photoelectron spectroscopy we can correlate the catalytic activ ity of $\mathrm{Cu}(110)$ with adsorbate coverages. In particular, we established a connection between the rate hysteresis and the adsorbate coverages for varying mixing ratios of methanol to oxygen. Two intermediates, methoxy and formate were identified. At low $\mathrm{T}$ the dominant intermediate is formate. The $c(2 \times 2)$ we see in LEED can be assigned to this species. Methoxy always only covers a minor part of the surface but this species remains detectable up to $\sim 600 \mathrm{~K}$. Two oxygen states were found: chemisorbed oxygen and a second state which could not be identified clearly but which dominates at high temperature. The reactivity of chemisorbed oxygen depends strongly on the coverage and on the island distribution. High coverages inhibit the reaction and large oxygen islands are less reactive. This latter finding supports the idea that only the edge atoms of the oxygen islands are reactive and that methoxy can spontaneously decompose towards formaldehyde at elevated temperatures if free $\mathrm{Cu}$ sites are accessible. We also found carbonaceous species which are reactive and which probably originate from reaction sidepaths and partially also from contamination. In order to test the consistency of the data with a mechanistic scheme, simulations with a realistic mathematical model are required.

\section{Acknowledgements}

This work was supported by the DFG under the priority program 1091 "Bridging the gap between ideal and real systems in heterogeneous catalysis".

\section{References}

1 C. N. Satterfield, Heterogeneous Catalysis in Practice. (McGraw Hill, New York, 1980).

J. Walker, Formaldehyde. (Reinhold, Amsterdam, 1964).

J. Walker, Encyclopedia of Industiral Chemistry. (Ullmann, Weinheim, 1982).

P. L. Hansen, J. B. Wagner, S. Helveg, J. R. RostrupNielsen, B. S. Clausen, and H. Topsoe, Science 295, 2053 (2002).

M. M. Günter, T. Ressler, B. Bems, C. Büscher, T. Genger, O. Hinrichsen, M. Muhler, and R. Schlögl, Catal. Lett. 71, 37 (2001).

C. L. Thomas, Catalytic Processes and Proven Catalysts. (Academic Press, New York, 1970).

I. E. Wachs and R. J. Madix, J. Catal. 53, 208 (1978).

A. F. Carley, A. W. Owens, M. K. Rajumon, M. W.

Roberts, and S. D. Jackson, Catal. Lett. 37 (1-2), 79

(1996).

S. M. Francis, F. M. Leibsle, S. Haq, N. Xiang, and M. Bowker, Surf. Sci. 315, 284 (1994).

F. M. Leibsle, S. M. Francis, S. Haq, and M. Bowker, Surf. Sci. 318, 46 (1994).

S. L. Silva, R. M. Lemor, and F. M. Leibsle, Surf. Sci. 421, 135-145 (1999).

S. L. Silva, R. M. Lemor, and F. M. Leibsle, Surf. Sci. 421, 146-156 (1999).

A. F. Carley, P. R. Davies, G. G. Mariotti, and S. Read, Surf. Sci. 364, 525 (1996).

M. Bowker, Top. Catal. 3 (3-4), 461 (1996).

15 P. R. Davies and G. G. Mariotti, J. Phys. Chem. 100, 19975 (1996).

16 P. R. Davies and G. G. Mariotti, Catal. Lett. 43, 261 (1997).

17 H. Werner, D. Herein, G. Schulz, U. Wild, and R. Schlögl, Catal. Lett. 49, 109 (1997).

18 A. Knop Gericke, M. Haevecker, T. Schedel-Niedrig, and R. Schlögl, Catal. Lett. 66, 215 (2000).

19 A. Knop-Gericke, M. Hävecker, T. Schedel-Niedrig, and R. Schlögl, Topics Catal. 15 (1), 27 (2001).

20 T. Schedel-Niedrig, M. Hävecker, A. Knop-Gericke, and R. Schlögl, Phys. Chem. Chem. Phys. 2 (15), 3473 (2000).

21 T. Schedel-Niedrig, T. Neisius, I. Böttger, E. Kitzelmann, G. Weinberg, D. Demuth, and R. Schlögl, Phys. Chem. Chem. Phys. 2 (10), 2407 (2000).

22 I. Boettger, T. Schedel-Niedrig, O. Timpe, R. Gottschall, M. Hävecker, T. Ressler, and R. Schlögl, Chem. Eur. J. 6 (10), 1870 (2000).

23 V. I. Bukhtiyarov, I. P. Prosvirin, E. P. Tikhomirov, V. V. Kaichev, A. M. Sorokin, and V. V. Evstigneev, React. Kinet. Catal. Lett. 79 (1), 181 (2003).

24 I. P. Prosvirin, E. P. Tikhomirov, A. M. Sorokin, V. V. Kaichev, and V. I. Bukhtiyarov, Kinet. Catal. 44 (5), 662-668 (2003).

25 H. Bluhm, M. Haevecker, A. Knop Gericke, E. Kleinmenov, R. Schlögl, D. Teschner, V. I. Bukhtiyarov, D. F. Ogletree, and M. Salmeron, J. Phys. Chem. B 108 , 14340 (2004) 
A. Kudelski and B. Pettinger, Surf. Sci. 566-568, 1007 (2004).

F. M. Leibsle, Surf. Sci 401, 153-161 (1998).

F. M. Leibsle, S. M. Francis, R. Davis, N. Xiang, S. Haq, and M. Bowker, Phys. Rev. Lett. 72 (16), 2569 (1994).

S. L. Silva, A. A. Patel, T. M. Pham, and F. M. Leibsle, Surf. Sci. 441, 351 (1999).

S. L. Silva, T. M. Pham, A. A. Patel, S. Haq, and F. M. Leibsle, Surf. Sci. 452, 79-94 (2000).

S. Poulston, A. H. Jones, R. A. Bennett, and M. Bowker, J. Phys. Condens. Mat. 8, 765-771 (1996).

A. H. Jones, S. Poulston, R. A. Bennett, and M. Bowker, Surf. Sci. 380 (1), 31 (1997).

M. Bowker, S. Poulston, R. A. Bennett, P. Stone, A. H. Jones, S. Haq, and P. Hollins, J. Molec. Catal. A 131 (1-3), 185 (1998).

L. Zhou, S. Günther, and R. Imbihl, J. Catal. 232, 295 (2005).

L. Zhou, S. Günther, and R. Imbihl, J. Catal. 230, 166 (2005).

R. Feidenhansl and I. Stensgaard, Surf. Sci. 133, 453 (1983). Solid Films 157, 351 (1988).

J. Finster, D. Schulze, F. Bechstedt, and A. Meisel, Surf. Sci. 152/153, 1063 (1985). 